NASA/TM-1998-208817

\title{
A Hazardous Gas Detection System for Aerospace and Commercial Applications
}

G.W. Hunter, P.G. Neudeck, and L.-Y. Chen

Lewis Research Center, Cleveland, Ohio

D.B. Makel

Makel Engineering, Chico, California

C.C. Liu and Q.H. Wu

Case Western Reserve University, Cleveland, Ohio

D. Knight

Cortez III Service Corporation, Cleveland, Ohio

Prepared for the

34th Joint Propulsion Conference and Exhibit cosponsored by AIAA, ASME, SAE, and ASEE

Cleveland, Ohio, July 12-15, 1998

National Aeronautics and

Space Administration

Lewis Research Center 


\section{Acknowledgments}

The authors would like to acknowledge the helpful discussions with Dr. W.D. Williams, Dr. Jih-Fen Lei, Dr. Herbert Will, Dr. David Larkin, and Dr. Daniel L.P. Ng of NASA LeRC, W.T. Powers and Martin Johnson of NASA Marshall Space Flight Center, Roselle Hanson and Greg Hall of Kennedy Space Center, and the technical assistance of D. Androjna and C. Salupo of Cortez III/NASA LeRC. L. Chen is a NRC Fellow with Gary Hunter as an advisor.

Available from

NASA Center for Aerospace Information 7121 Standard Drive

Hanover, MD 21076

Price Code: A03
National Technical Information Service 5285 Port Royal Road Springfield, VA 22100 Price Code: $\mathrm{A} 03$ 


\title{
A HAZARDOUS GAS DETECTION SYSTEM FOR AEROSPACE AND COMMERCIAL APPLICATIONS
}

\author{
G.W. Hunter, P.G. Neudeck, and L.-Y. Chen \\ National Acronautics and Space Administration \\ Lewis Research Center \\ Cleveland, Ohio 44135 \\ D.B. Makel \\ Makel Engineering \\ Chico, California 95973 \\ C.C. Liu and Q.H. Wu \\ Case Western Reserve University \\ Electronics Design Center \\ Cleveland. Ohio 44106 \\ D. Knight \\ Cortez III Service Corporation \\ Cleveland. Ohio 44135
}

\begin{abstract}
The detection of explosive conditions in aerospace propulsion applications is important for safety and economic reasons. Microfabricated hydrogen, oxygen, and hydrocarbon sensors as well as the accompanying hardware and software are being developed for a range of aerospace safety applications. The development of these sensors is heing done using MEMS (Micro ElectroMechanical Systems) based technology and SiC-based semiconductor technology. The hardware and software allows control and interrogation of each sensor head and reduces accompanying cabling through multiplexing. These systems are being applied on the $\mathrm{X}-33$ and on an upcoming STS-95 Shuttle mission. A number of commercial applications are also being pursued. It is concluded that this MEMS-based technology has significant potential to reduce costs and increase safety in a variety of aerospace applications.
\end{abstract}

\section{INTRODUCTION}

The detection of explosive combinations of fucl and oxygen is important in the aerospace industry for safety monitoring applications. Specifically, leaks in fuel tank systems can lead to hazardous situations. If the leak location and magnitude cannot be determined in a timely manner, the consequences can range from expensive delays to loss of life. For example, in 1990 , the leaks on the Space Shuttle while on the launch pad temporarily grounded the lleet until the leak source could be identified.
In response to the hydrogen leak problems in particular, NASA endeavored to improve propellant leak detection capabilities during assembly, pre-launch operations, and flight. The objective has been to reduce the operational cost of assembling and maintaining hydrogen delivery systems by using automated detection systems. Specifically, efforts were made to develop an automated hydrogen leak detection system using point-contact hydrogen sensors. However, no commercial sensors existed at that time that operated satisfactorily in this application. The reason for this is the conditions in which the sensor must operate.

The hydrogen sensor must be able to detect hydrogen from low concentrations through the lower explosive limit (LEL) which is $4 \%$ in air. The sensor must be able to survive exposure to $100 \%$ hydrogen without damage or change in calibration. Further, the sensor may be exposed to gases emerging from cryogenic sources. Thus, sensor temperature control is necessary. Operation in inert environments is necessary since the sensor may have to operate in areas purged with helium. If a number of sensors are to be placed in an area, then size, weight, and power consumption for each sensor becomes an issue. Commercially available sensors, which often needed oxygen to operate or depended upon moisture', did not meet the needs of this application and thus the development of new types of hydrogen sensors was necessary. ${ }^{2}$

However, it is not just the concentration of hydrogen that determines if an explosive condition exits but the corresponding concentration of oxygen as well. 
Thus, the simultaneous measurement of oxygen as well as hydrogen is desirable in safety applications. Further, the needs of future aerospace applications may require not only the detection of hydrogen but other hydrocarbon fuels which may be used as propellants. For example, the use of methane or kerosene as propulsion fuels means that the detection of these hydrocarbons in inert environments may be necessary for leak detection for future propulsion systems. These sensor technologies would have to meet the same requirements as the hydrogen sensor technology of minimal size, weight. and power consumption. Miniaturized, integrated hydrocarbon leak detection technology of this type does not presently exist.

In conjunction with improved sensor technology, a complete leak detection system also needs accompanying hardware and software. Being able to multiplex the signal from a number of sensors so as to "visualize" the magnitude and location of the leak is necessary. The hardware should be multiplexed to limit the amount of cabling necessary to operate the system and intelligent control of each sensor head is required.

NASA Lewis Research Center (LeRC), Case Western Reserve University (CWRU), and Makel Engineering Inc. (MEI) are actively involved in developing leak sensor technology as well as the corresponding hardware and software to meet the needs of aerospace applications. The sensor fabrication is performed using MEMS (Micro ElectroMechanical Systems) based technology i.e. using silicon ( $\mathrm{Si}$ ) integrated circuit processing technology. This results in miniaturized sensors which can be micro-machined for minimal size, weight, and power consumption. Also being explored are sensors which use high temperature silicon carbide ( $\mathrm{SiC}$ ) semiconductors. Smart electronics are included with the system to provide temperature control for the sensor and to interpret the sensor output.

The purpose of this paper is to discuss the development of this technology. We will first discuss the development of hydrogen, oxygen, and hydrocarbon sensor technology. We will then discuss the hardware and software associated with the hydrogen sensor technology and the current application of this technology to X-33 applications and to the Space Shuttle mission STS-95. Potential commercial applications of these technologies are also discussed. It is concluded that the continued development of this technology will enable improved safety for flight propulsion applications.

\section{HYDROGEN DETECTION}

One component of the sensor development program at NASA LeRC and CWRU in conjunction with MEI involves the development of palladium (Pd) alloy Schottky diodes on silicon ( $\mathrm{Si}$ ) substrates. These sensors are designed to detect hydrogen $\left(\mathrm{H}_{2}\right)$ in space applications. This type of sensor is based on metaloxide-semiconductor (MOS) technology such as that used in the semiconductor electronics industry. The gas sensing MOS structures are composed of a hydrogen sensitive rnetal deposited on an insulator adherent to a semicondictor. This forms a Schoutky diode in the case of a very thin layer of insulator. The most common MOS stricture used for hydrogen detection is the $\mathrm{Pd}-\mathrm{SiO}_{2}-\mathrm{Si}$ structure. Hydrogen disassociates on the $\mathrm{Pd}$ surface and diffuses to the $\mathrm{Pd}-\mathrm{SiO}_{2}$ interface affecting the electrenic properties of the MOS system. ${ }^{3}$ The use of pure $\mathrm{Pd}$ at near room temperatures as the hydrogen sensitive rietal is problematic for several reasons. The most sericus of these involves a phase change that occurs at high hydrogen concentrations which can lead to hysteres is or film damage.

Schottky diodes using Pd alloys as the hydrogen sensitive metal are presently being fabricated. The first generation of these sensors used palladium silver (PdAg). The use of PdAg in hydrogen sensing applications was pioneered by Hughes. ${ }^{+}$Palladium silver has advantages over Pd. Palladium silver is more resistant to damage from exposure to high hydrogen concentration than I'd. Furthermore, the alloy has faster response times than Pd.

The sensor structure is shown in Figure 1 with a picture of the packaged sensor. The structure includes a Pd alloy Schottky diode, a temperature detector, and a heater all ncorporated in the same chip. The sensor is fabricated using a n-type silicon wafer on which approximate $y 50 \AA$ of silicon dioxide $\left(\mathrm{SiO}_{2}\right)$ is thermally grown in the sensor region. The heater and temperature detector a e platinum covered with $\mathrm{SiO}_{2}$. Gold leads are applied by thermal compression bonding and the sensor is riounted on a TO5 header or on a ceramic flat package. The surface area of the Schottky diode is $6.1 \times 10^{-3} \mathrm{~cm}^{2}$ and the complete sensor dimensions are approximately $2.2 \mathrm{~mm}$ on a side. The response of the Schottky diodes was determined by measuring the diode's revel se current. 

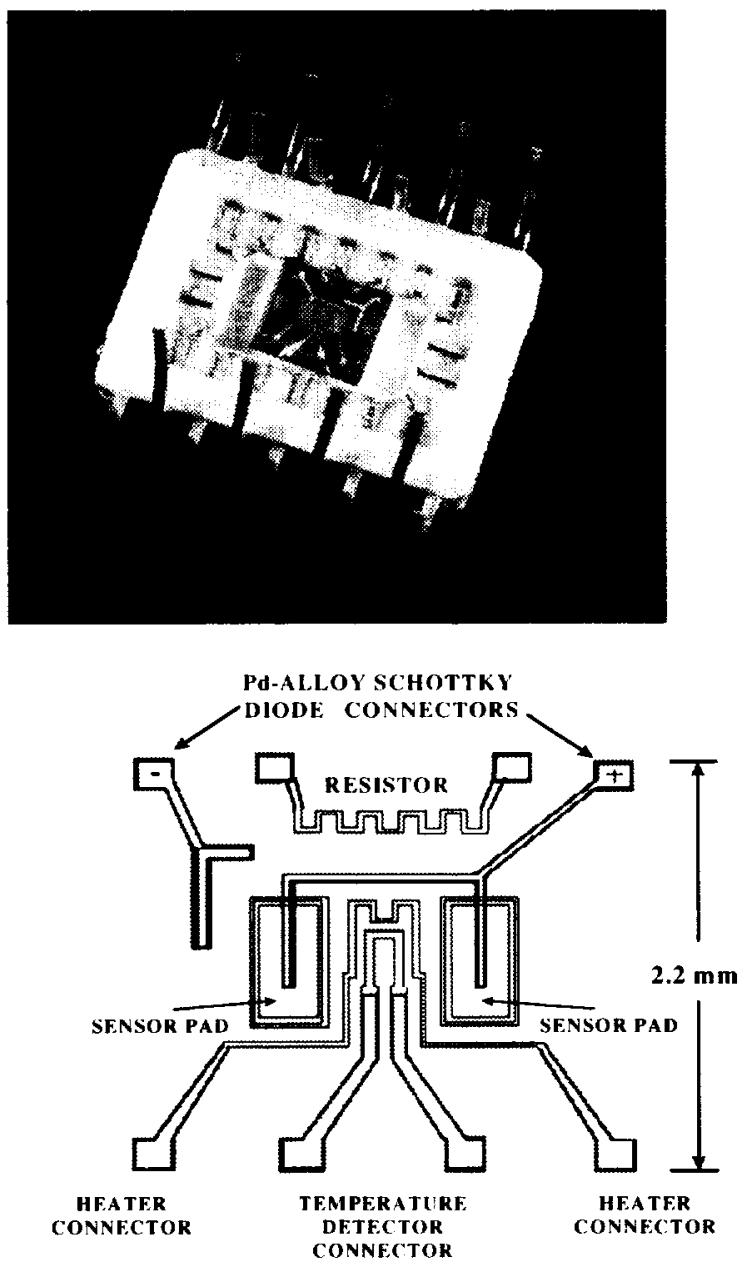

Figure 1. Design and complete package of a wide range $P d$ alloy hydrogen sensor. The sensor package includes a Schottky diode hydrogen sensor, a temperature detector, and a heater. A hydrogen sensitive resistor is added for $X$ 33 applications (see pg. 5).

The properties of the PdAg sensor make it very useful for applications where sensing small amounts of hydrogen is necessary. The sensor responds in an inert environment (no oxygen) to the presence of hydrogen. The presence of oxygen decreases the sensor response but the sensor is still sensitive to low concentrations of hydrogen. $^{5-6}$ The sensor response is large, rapid, and repeatable. If quick recovery is necessary, then the sensor should be operated in oxygen containing gases. If detection of hydrogen is required without rapid recovery, then this sensor can also be used in inert environments. The sensor responds to hydrogen across a wide concentration range with a signal and response time that is temperature dependent. This sensor can be used to monitor leaks in a multipoint leak detection scheme involving a number of these sensors. Further, this $\mathrm{PdAg}$ sensor has been shown to have a sensitivity and response comparable to that of a mass spectrometer. ${ }^{7}$

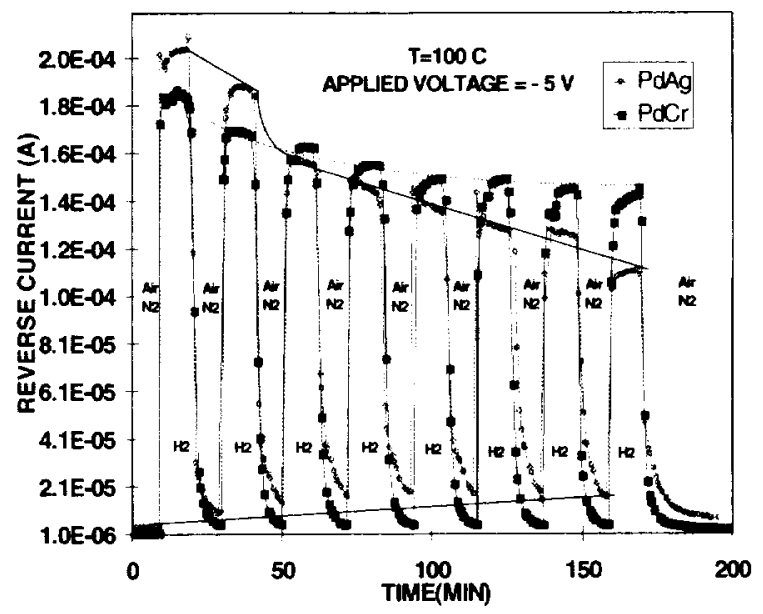

Figure 2. The response of PdAg and PdCr Schottky diode sensors at $100 \mathrm{C}$ to repeated exposures of 9 minutes of air, 1 minute of nitrogen, 10 minutes of $100 \%$ hydrogen, and 1 minute of nitrogen. The $\mathrm{PdCr}$ diode shows a more repeatable baseline and a more stable response than the $\mathrm{PdAg}$ diode.

Although the PdAg sensor showed excellent properties for a number of applications, exposure to higher temperatures and higher hydrogen concentrations changed the sensor calibration and occasionally led to the sensor failure. ${ }^{5-6}$ An example of the degradation of the PdAg sensor response at higher temperatures and higher hydrogen concentrations is shown in Figure 2. The response of a $\mathrm{PdAg}$ sensor to $100 \%$ hydrogen at $100 \mathrm{C}$ for several cycles is shown. The sensor response decreases with the number of exposures and with a much poorer recovery to the original baseline after each cycle.

One significant reason for this behavior may be seen in Figure 3. Figure 3 shows an optical micrograph (400x) of an as-deposited PdAg sensing pad of the Schottky diode (Figure 3a) and a sensing pad from the $\mathrm{PdAg}$ sensor (Figure $3 \mathrm{~b}$ ) characterized at $100 \mathrm{C}$ in $100 \%$ hydrogen in Figure 2. The as-deposited PdAg film is uniform in surface features and the edges of the film are straight and rectangular. In contrast, the PdAg film in the characterized sample shows signiticant peeling of the PdAg near the edges of the sensor pads rectangular pattern and a significant amount of surface features. EDAX (Energy Dispersion Analysis of $X$-Radiation) analysis of the region near the edge of the sensor pad in Figure 3b suggests that the PdAg has been removed from the surface leaving only the $\mathrm{SiO}_{2}$ layer. Thus, a likely reason for the change in the sensor response with heating and exposure to $100 \%$ hydrogen is this delamination of the $\mathrm{PdAg}$ sensing film near the edges of the sensor pad. 
Therefore, the sensor structure needs to be stabilized for operation in $100 \%$ hydrogen (as in the Shuttle application). This led to the development of the next generation of sensor. This sensor, which uses $\mathrm{PdCr}$ as the hydrogen sensitive alloy, is in its later stages of development. The response of the $\mathrm{PdCr}$ Schottky diode to $100 \%$ hydrogen at $100 \mathrm{C}$ is also shown in Figure 2. The PdCr sensor is much more stable than the PdAg sensor under these conditions; the $\mathrm{PdCr}$ diode response to 100\% hydrogen is nearly consistent (after the initial exposures) with an equally consistent return to a common baseline. The optical micrograph of the corresponding $\mathrm{PdCr}$ sensor pad (Figure $3 \mathrm{c}$ ) shows some degradation of the film surface. However, the $\mathrm{PdCr}$ film does not exhibit the peeling of the sensing film near the edge of the sensing pad as was seen with the PdAg film.

Parallel tests to those of Figure 2 were conducted at $100 \%$ hydrogen with a different $\mathrm{PdCr}$ sensor and an operating temperature of $75^{\circ} \mathrm{C}$. The $\mathrm{PdCr}$ sensor response was similar to that seen in Figure 2. However, as seen in Figure 3d. there is significantly less surface structure on the sensor film surface with generally good adhesion of the film to the rectangular boundaries of the sensor pad.

Therefore, $\mathrm{PdCr}$ shows significantly improved stability and response over $\mathrm{PdAg}$ at $100 \mathrm{C}$. Operation at $70 \mathrm{C}$ results in more stable surface features than $100 \mathrm{C}$ operation. The results of these tests and other testing suggest that $\mathrm{PdCr}$ is better for applications where the sensor is exposed to higher hydrogen concentrations while PdAg can be used for lower hydrogen concentration applications.

This has led to the use of $\mathrm{PdCr}$ both as a hydrogen sensitive resistor and a Schottky diode material to expand the detection range of the sensor for X-33 applications (Figure 1): a Schottky diode provides sensitive detection of low concentrations of hydrogen while the resistor provides sensitivity up to $100 \%$ hydrogen.

The resistors have been fabricated so as to have the highest sensitivity to concentrations of hydrogen greater than $1 \%$. This is shown in Figure 4 for 7 resistive sensors exposed to hydrogen in nitrogen from $10 \mathrm{ppm}$ to $1 * 10^{6}$ $\mathrm{ppm}(100 \%)$. The resistor response is conditioned by electronics to result in changes in millivolts $(\mathrm{mV})$ as shown in the Figure. The signal increases significantly with higher concentrations of hydrogen and the response of the 7 resistors is seen to be generally uniform.

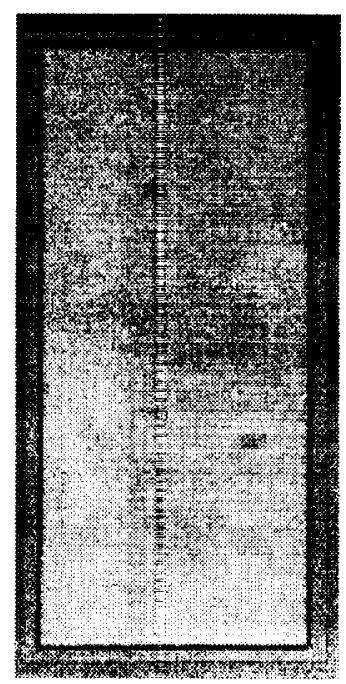

a) PdAg

As-deposited

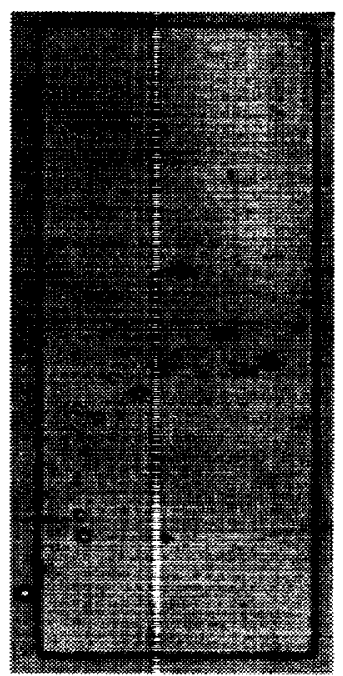

c) $\mathrm{PcCr}$

After testing at $100^{\circ} \mathrm{C}$

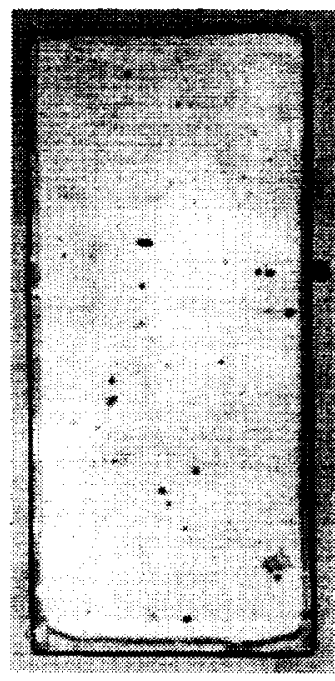

b) $\mathrm{PdAg}$

After testing at $100 \mathrm{C}$

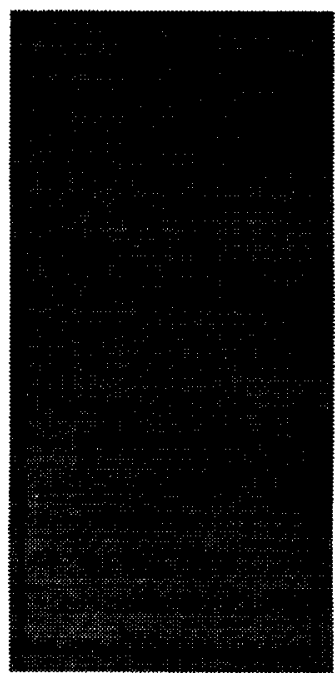

d) $\mathrm{PdCr}$

After testing at $70^{\circ} \mathrm{C}$
Figure 3. Optical Micrographs of the sensor pad of: a) PdAg sensır as-deposited; b) PdAg sensor after heating and characterization in $100 \% \mathrm{H}_{2}$ at $100 \mathrm{C}$; c) $\mathrm{PdCr}$ sensor after heating and characterization in $100 \% \mathrm{H}_{2}$ at $100 \mathrm{C}$; d) PdCr sensor after heating and characterization in $100 \%$ $\mathrm{H}_{2}$ at $75 \mathrm{C}$. The PdCr sensor does not show delamination of the sensir film near the edges of the sensor pad evident with the Pc Ag-based sensor. 


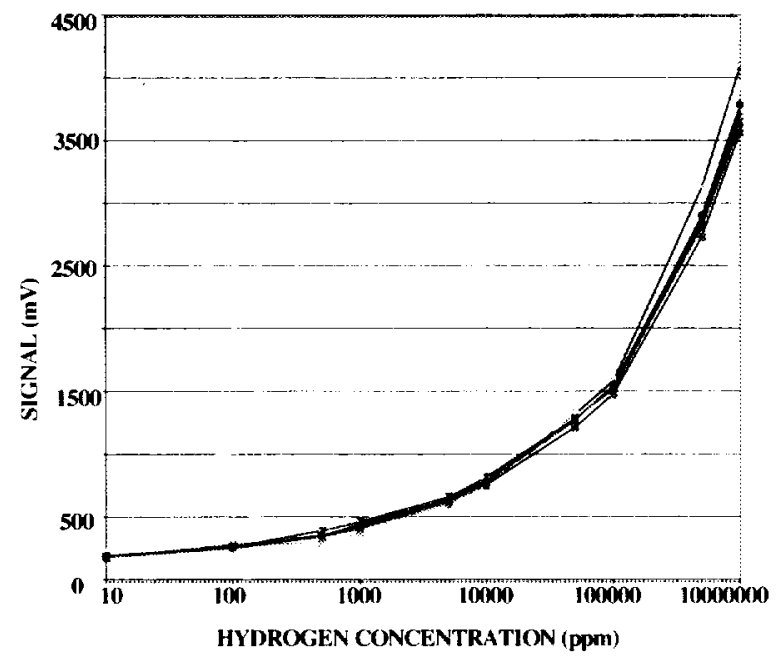

Figure 4 . PdCr hydrogen resistor response to different hydrogen gas concentrations.

The response of both the Schottky diode and the resistor on the same chip is shown in Figure 5. The temperature is held constant at $70 \mathrm{C}$ while the sensor package is exposed to hydrogen concentrations from $1000 \mathrm{ppm}$ to $100 \%$. The output is signal conditioned and presented in millivolts. The signal of the diode shows the highest sensitivity and quickest recovery times at lower concentrations while the resistor provides high sensitivity at higher concentrations of hydrogen.

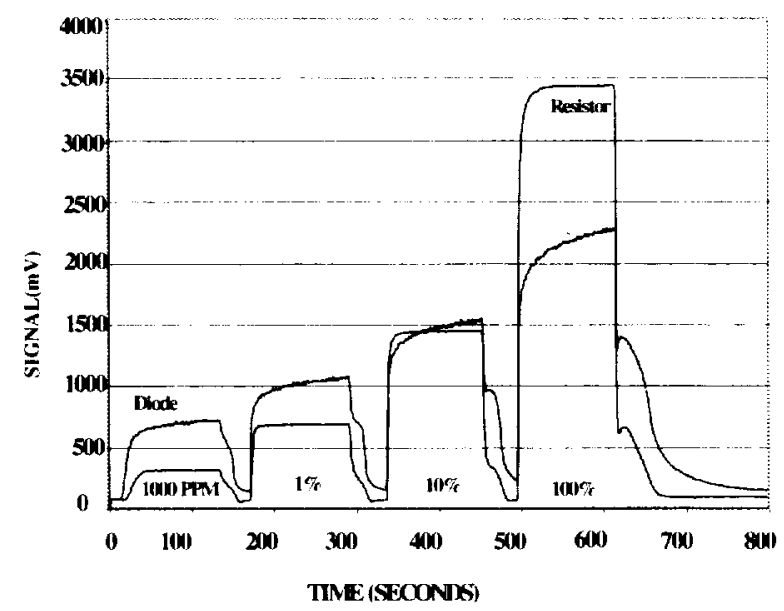

Figure 5. Typical sensor response and recovery to step changes in hydrogen concentration for a temperature controlled PdCr Schottky diode and resistor.
Therefore, two alloys are used to measure hydrogen in inert environments. Palladium silver can be used for sensitive measurement of low concentrations of hydrogen while $\mathrm{PdCr}$ can be used as a diode and resistor material for a range of concentrations up to $100 \%$ hydrogen.

\section{OXYGEN DETECTION}

The development of a microfabricated $\mathrm{O}_{2}$ sensor has been initiated to complement the existing hydrogen sensor technology. Commercially available oxygen sensors are typically electrochemical cells using zirconium dioxide $\left(\mathrm{ZrO}_{2}\right)$ as a solid electrolyte and $\mathrm{Pt}$ as the anode and cathode. ${ }^{8}$ The anode is exposed to a reference gas (usually air) while the cathode is exposed to the gas to be detected. Zirconium dioxide becomes an ionic conductor of $\mathrm{O}^{-}$at temperatures of $600 \mathrm{C}$ and above. This property of $\mathrm{ZrO}_{2}$ to ionically conduct oxygen means that the electrochemical potential of the cell can be used to measure the ambient oxygen concentration at high temperatures. However, operation of these commercially available sensors in this potentiometric mode limits the range of oxygen detection. Typically, the potentiometric mode has limited sensitivity above $1 \%$ oxygen. Further, the current manufacturing procedure of this sensor, using sintered $\mathrm{ZrO}_{2}$, is relatively labor intensive and costly resulting in a complete sensor package with a power consumption on the order of several watts.

The objective of this research is to develop a zirconium dioxide solid electrolyte oxygen sensor using microfabrication and micromachining techniques. A schematic of the sensor design is shown in Figure 6 with a picture of the packaged sensor. A diaphragm region is micro-machined by etching beneath the sensing area. Microfabricating the sensor components onto the diaphragm region allows the sensor to be small in size and have decreased energy consumption and time for thermal equilibrium. When operated in the amperometric mode, the current of this cell is a linear function of the ambient oxygen concentration. This linear response to oxygen concentration significantly increases the oxygen detection range of the sensor. A chamber structure with a well-defined orifice is micromachined to cover the sensing area. This orifice provides a pathway to control oxygen diffusion which is important in amperometric measurements. This orifice also protects the integrity of the sensing electrode from impinging particles. Preliminary testing of a complete oxygen sensor has been accomplished and further improvements on the design are planned. 

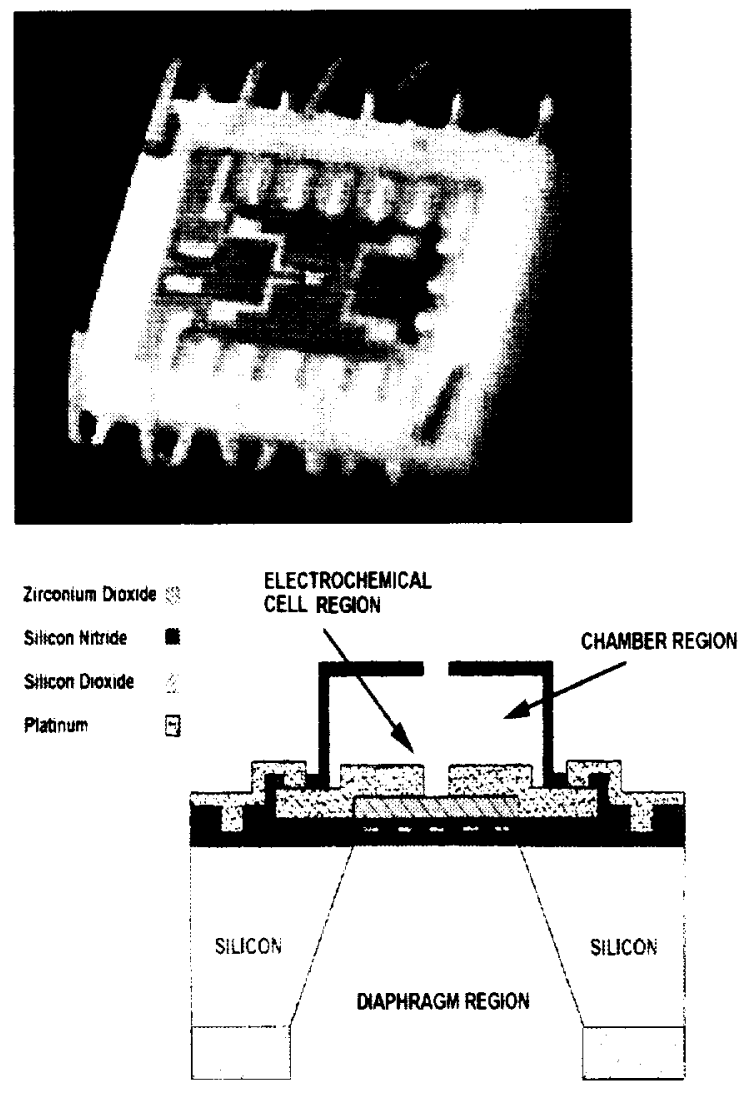

Figure 6. Design and complete package of an amperometric ZrO2 Oxygen Sensor.

The completed oxygen sensor will be incorporated into one sensor package with the existing $\mathrm{PdCr}$ hydrogen sensor. The combined system will be able to measure the concentration of hydrogen and oxygen simultaneously. The ratio of the hydrogen to oxygen concentration will not only determine if there is a leak but if there is an explosive condition. However, if the fuel is not hydrogen, leak detection of the fuel in inert environments using point-contact sensors is not presently commercially available. Thus, the development of corresponding hydrocarbon leak sensor technology is necessary.

\section{HYDROCARBON DETECTION}

The development of hydrocarbon sensors for use in salety applications has centered on the development of a stable SiC-based Schottky diode. There are significant advantages in a number of gas sensing applications to using $\mathrm{SiC}$ as the semiconductor rather than $\mathrm{Si}^{.}$
These advantages are due to the improved material properties of $\mathrm{SiC}$ over $\mathrm{Si}$ such as high temperature semicondector operation, superior mechanical toughness, and increased thermal conductivity. The detection of gases such as hydrocarbons, which decompose at high temperatures, is facilitated by heating the sensor to the gas decomposition temperature. ${ }^{10-12}$ The hydrocarbons then dissociate and produce atomic hydrogen. The resulting atomic hydrogen affects the sensor output in the same way as molecular hydrogen.

The SiC-based Schottky diode structure under development has begun with $\mathrm{Pd}$ on $\mathrm{SiC}(\mathrm{Pd} / \mathrm{SiC}) \mathrm{MS}$ structures. Direct contact between the gas sensitive catalytic metal and the semiconductor allows changes in the catalytic metal to have maximum effect on the semiconductor. Studies of this baseline system help determine limits of diode sensitivity, potential material interactions between $\mathrm{Pd}$ and $\mathrm{SiC}$, and whether a barrier layer between the $\mathrm{Pd}$ and $\mathrm{SiC}$ is necessary for long-term sensor staility. The details of this work are reviewed elsewhere ${ }^{11}$ The sensor detects hydrogen and hydrocarbsons in inert or oxygen containing environments.

Figure 7 illustrates the advantage of $\mathrm{SiC}$ over $\mathrm{Si}$ in hydrocarbon sensing applications. Shown is the zero bias capacitive response of a $\mathrm{Pd} / \mathrm{SiC}$ Schottky diode to one hydrocarbon, propylene, at a range of temperatures. The sensor temperature is increased from $100^{\circ} \mathrm{C}$ to $400^{\circ} \mathrm{C}$ in steps of $100^{\circ} \mathrm{C}$ and the response of the sensor is observed. At a given temperature. the sensor is exposed 10 air for 20 minutes, $N_{2}$ for 20 minutes. 360 ppm of propylene in $N_{2}$ for 20 minutes, $N_{2}$ for 10 minutes, and then 10 minutes of air.

The nagnitude of sensor response to $360 \mathrm{ppm}$ propylene depends strongly on the operating temperature. A sensor operating temperature of $100^{\circ} \mathrm{C}$ is too low for propylene to dissociate on the Pd surface, so the der ice does not respond at all. The three other curves for $200^{\circ} \mathrm{C}, 300^{\circ} \mathrm{C}$, and $400^{\circ} \mathrm{C}$ show that elevating the temp srature increases the sensor's response to propylene The presence of propylene can be detected at any of these higher temperatures with $200^{\circ} \mathrm{C}$ being the minimum operating temperature determined in this study. Since the standard long-term operating temperatu e of $\mathrm{Si}$ is usually below $200^{\circ} \mathrm{C}$, these results demonstr: te the significant advantages of using $\mathrm{SiC}$ rather than $\mathrm{Si}$ in gas sensing applications. 


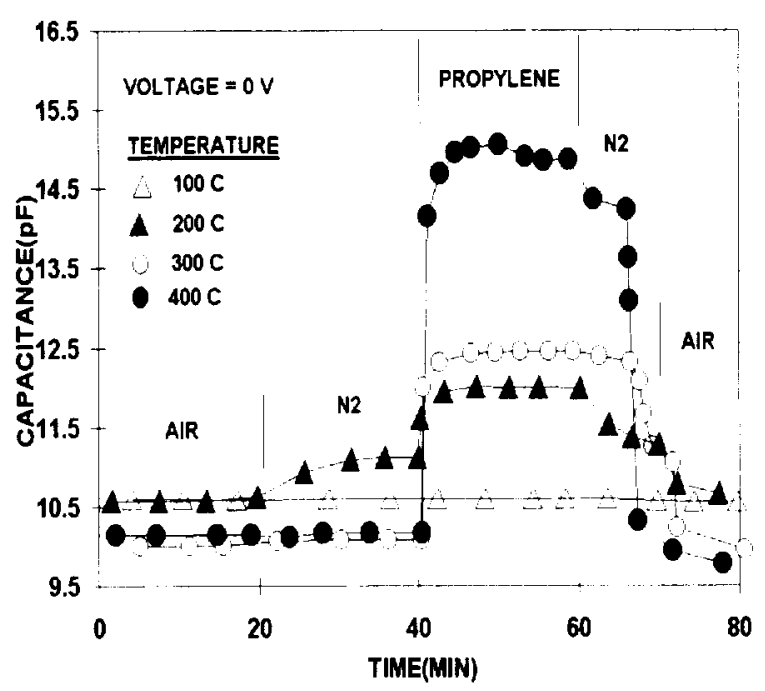

Figure 7. The temperature dependence of the zero bias capacitance to various gas mixtures of a $\mathrm{Pd} / \mathrm{SiC}$ Schottky diode. The response to propylene is seen to be strongly temperature dependent.

However, the $\mathrm{Pd} / \mathrm{SiC}$ sensor response is affected by extended high temperature heating. Prolonged heating at $425 \mathrm{C}$ has been shown to change the sensor properties and to decrease sensor sensitivity. "Even after heating at $425 \mathrm{C}$ in air for 140 hours, the $\mathrm{Pd} / \mathrm{SiC}$ Schottky diode is still very sensitive to the presence of hydrogen: a factor of 1000 change in forward current is observed upon exposure to $1000 \mathrm{ppm}$ hydrogen in He. The reason for this change in diode properties is likely due to reactions between the $\mathrm{Pd}$ and $\mathrm{SiC}$ at the interface upon heating. Nonetheless, efforts have been underway to stabilize the sensor structure for long-term, high temperature operation.

One new structure ${ }^{1,3}$ demonstrated which has improved stability over that of $\mathrm{Pd} / \mathrm{SiC}$ is $\mathrm{PdCr}$ directly deposited on $\mathrm{SiC}(\mathrm{PdCr} / \mathrm{SiC})$. The advantages of $\mathrm{PdCr}$ as a high temperature alloy have been explored extensively in strain gage applications. ${ }^{1+}$ It is a stable high temperature material which is able to provide static strain measurements at temperatures up to $1100^{\circ} \mathrm{C}$. However, its use in a gas-sensing $\mathrm{SiC}$-based structure depends on not only its inherent stability but also such factors as the alloy"s reactivity to $\mathrm{SiC}$ and the catalytic interactions of $\mathrm{PdCr}$ alloy with the gases to be measured.

The response of a $\mathrm{PdCr} / \mathrm{SiC}$ diode to long term heating of 250 hours at $425^{\circ} \mathrm{C}$ showed improved stability over $\mathrm{Pd} / \mathrm{SiC}$. Monitoring of the sensor performance periodically during the heating period suggests the $\mathrm{PdCr} / \mathrm{SiC}$ diode has improved stability over the $\mathrm{Pd} / \mathrm{SiC}$ structure. The sensor is characterized at $100^{\circ} \mathrm{C}$ after heating at $425^{\circ} \mathrm{C}$. Current-time measurements at $0.7 \mathrm{~V}$ were taken as the sensor was exposed to 20 minutes of air, 20 minutes in nitrogen $\left(\mathrm{N}_{2}\right), 20 \mathrm{~min}$ utes of $120 \mathrm{ppm} \mathrm{H}_{2}$ in $\mathrm{N}_{2}\left(\mathrm{~N}_{2} / \mathrm{H}_{2}\right.$ mix $), 10$ minutes of $\mathrm{N}_{2}$, and then 10 minutes of air. After an initial break-in period of near 40 hours, the results show that the sensor response in hydrogen is relatively constant.

This is illustrated in Figure 8 where the diode response after 40 and 250 hours of heating is compared. Although the sensor baseline in air is much lower after 250 hours of heating than at 40 hours, the sensor current in the $\mathrm{N}_{2} / \mathrm{H}_{2}$ mix is the same within a factor of 3 . Thus, the diode's response to hydrogen after 250 hours of heating is nearly two orders of magnitude larger at this voltage than at 40 hours.

Therefore, the high sensitivity and improved stahility of the $\mathrm{PdCr} / \mathrm{SiC}$ sensor allows the sensitive detection of hydrogen. The use of $\mathrm{SiC}$ as a semiconductor expands the temperature range of hydrogen detection and also allows the detection of hydrocarbons. Testing of the PdCr alloy at high temperature is planned to determine the diode's sensitivity to a range hydrocarbons. Future work will also include packaging of the $\mathrm{SiC}$-based sensor for leak detection applications.

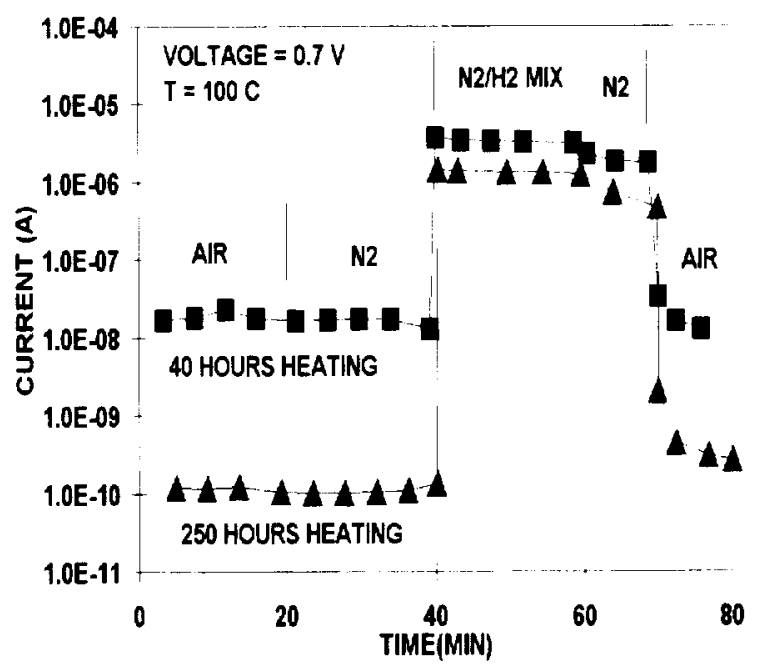

Figure 8. The forward current vs time at $100^{\circ} \mathrm{C}$ after 40 hours $(\square)$ and 250 hours $(\Delta)$ heating at $425^{\circ} \mathrm{C}$ in air of a PdCr/SiC Schottky diode. The diode show improved sensitivity with heating with nearly the same response to 120 ppm hydrogen in nitrogen. 


\section{SYSTEM DEVELOPMENT AND APPLICATION}

The initial incorporation of the PdAg sensor into hardware and software has been reported elsewhere. ${ }^{6}$ MEI. CWRU, and NASA LeRC have subsequently developed a "Smart Sensor" for hydrogen gas detection under an STTR contract from NASA MSFC. A broad range of operational system payoffs are possible with this type of complete leak detection system. These payoffs include: 1) Improved Integrated Vehicle Health Management (IVHM); 2) Improved safety and reliability: 3) Reduced sensor size and weight yielding reduced vehicle weight; 4) Cost effective method to instrument the vehicle.

Current aerospace applications of the $\mathrm{Pd}$ alloy sensors include the hydrogen leak detection systems for NASA's X-33 Flight Demonstrator and an up coming Space Shuttle technology demonstration flight for STS95. For these applications robust signal conditioning and control electronics have been developed to operate the sensor:. A block diagram of our desired functionality is show $n$ in Figure 9.

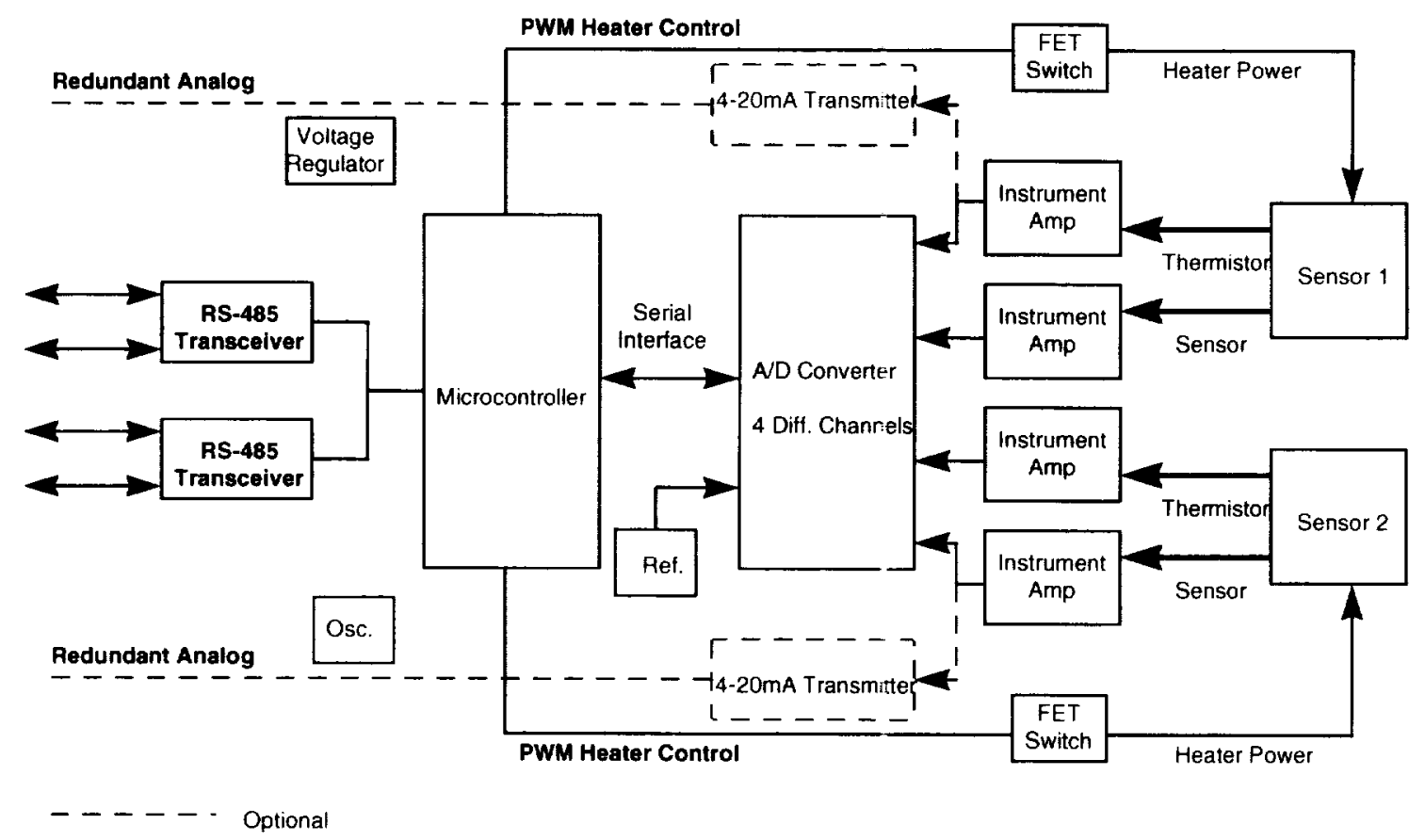

Figure 9. Smart Sensor Electronics Provides Signal Conditioning, Pov er Conditioning, Sensor Control, Calibration Storage, Conversion To Engineering Units and Digital Interface.

The Smart Sensor electronics currently consist of a power converter board, signal conditioning board, and a microcontroller board. The control system is based on an eight-bit microcontroller. Integrated microcontrollers are well suited for control applications of this nature due to its onboard peripherals, in particular the Programmable Counter Array. Several PCA channels are programmed to act as Pulse Width Modulators to control sensor heater elements. Another channel is used as a Watch Dog Timer to protect against errant firmware execution.
An external Address/Data bus allows for program fetches, dz ta storage in non-volatile SRAM, and access to the Anclog to Digital Converter. A reset device provides a reliable power-on reset to the CPU and also monitors ${ }^{\prime} \mathrm{cc}$. If $\mathrm{Vcc}$ is outside a predetermined range, the CPU $\mathrm{i}$, placed in reset until Vec returns to acceptable levels. Serial communication is provided, and both RS-232 and RS-485 levels are supported. Analog sensor signals are acquired from the sensor amplifier board using an analog to digital converter. Twelve-bit resolution ensu*es a high degree of accuracy. Sensor 
temperature data is used to provide closed loop control of the sensor temperature. The controller board is combined with a sensor amplifier board and a power supply board to produce a very compact data acquisition and control system. When assembled, the board stack measures approximately 1.3 " by 2.1 " by $1.2 "$.

NASA is planning to fly a network of six sensors on an upcoming Space Shuttle mission STS-95 as part of HDT-1 in November 1998 (Figure 10). The mission will evaluate new technologies to improve vehicle health monitoring. The "Smart" module to fly on this mission adds the functionality of an on-board microcontroller to provide all sensor control, conversion of data to engineering units. storage of calibration data, built-in-test functions, and communications.

The technology for this "Smart Sensor" for the STS-95 mission is significantly improved over previous designs. These improvements include a significant reduction in system integration with, for example, no centralized control system and a reduction in cabling requirements. The "Smart Sensor" performs all required sensor element control functions and provides a high level digital interface to the vehicle data system. These "Smart Sensor" modules requires only a four wire connection (two for power and two for RS-485 communications) and can be easily integrated existing avionics systems.

For the $\mathrm{X}-33$ program, a 20 sensor system is being developed for use on the purge vent doors. The sensors are integrated with an electronics module which provides signal conditioning electronics and an isolated 28 VDC DC/DC power conversion. The X-33 system is currently in qualification testing including EMI, vibration, and thermal cycle testing. The X-33 is scheduled for flight testing in 1999.

Future work will include the further miniaturization of the electronics package and associated housing. The use of ASIC (application specific integrated circuits) technology is envisioned to decrease the size and weight of the electronics while maintaining the same capabilities.

\section{COMMERCIAL APPLICATIONS}

MEI is continuing this work with potential application of hydrogen sensors in a variety of industrial environments. For example, use of a hydrogen sensor to detect degradation of the health of transformers is being explored. As electrical insulation in a transformer

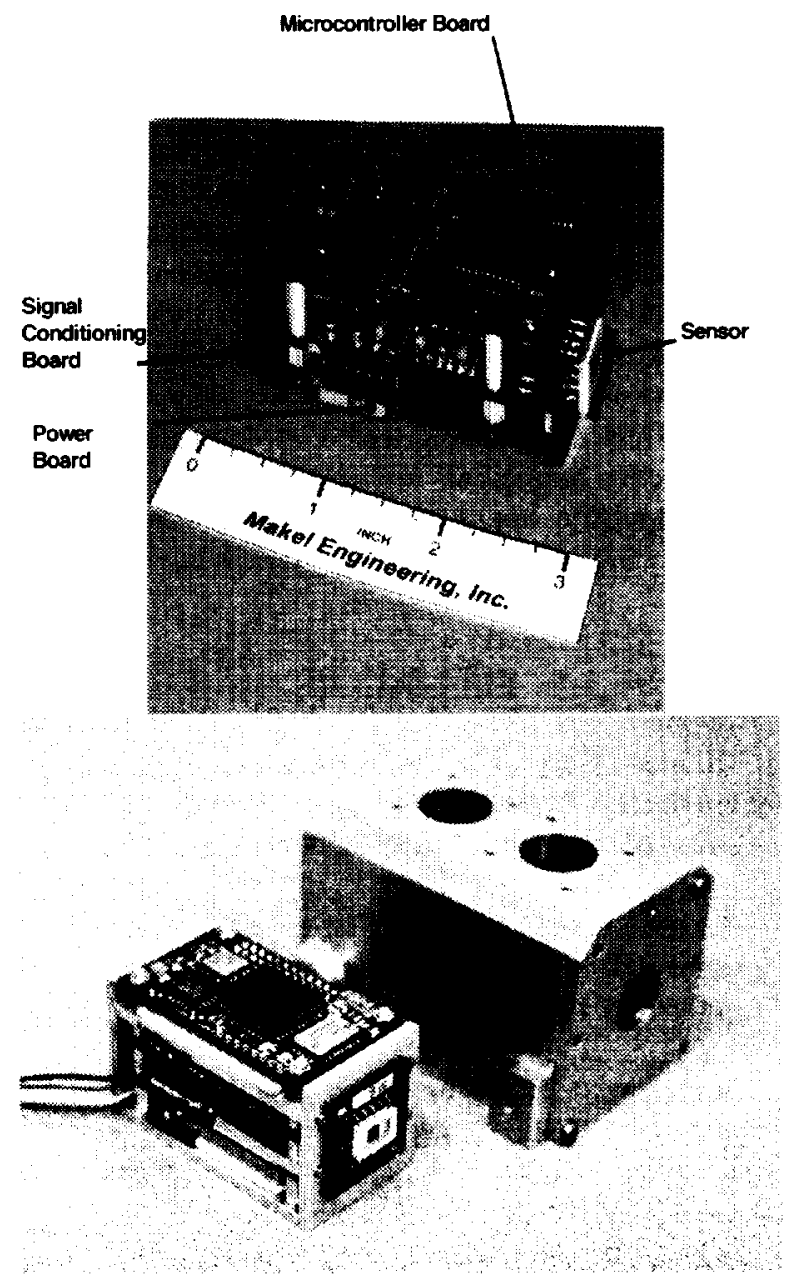

Figure 10. "Smart Sensor" Module developed by MEU/CWRU/NASA is being tested on STS-95 as part of HDT-1.

breaks down prior to its failure. hydrogen is released. Monitoring of hydrogen in-situ in these transformerscan provide early detection of transformer degradation and avoid costly catastrophic failure of transformers in the field. The PdAg sensors have already been applied to automotive leak testing applications ${ }^{6}$ and the complete product has been internationally recognized with a 1995 R\&D 100 Award. Other possible applications include the monitoring of hydrogen releases from fuel cells and industrial safety monitoring.

\section{SUMMARY}

Leak detection technology is heing developed for aerospace applications. This technology is based on microfabrication and micromachining (MEMS-based) technology and $\mathrm{SiC}$ semiconductor technology. The 
hydrogen sensor technology, using both $\mathrm{PdCr}$ alloys, has been well developed and is being applied on the X-33 and on the upcoming Space Shuttle STS-95 mission. Oxygen sensor technology is also being developed to complement the hydrogen sensor technology. This micromachined oxygen sensor uses $\mathrm{ZrO}_{2}$ to amperometrically measure the oxygen over a wide concentration range. Hydrocarbon sensor technology to detect leaks alternate fuels are also under development to meet the needs of future aerospace propulsion applications. Thus, miniaturized leak detection technology is already being applied to improve the safety of aerospace propulsion applications and integration of this technology in future propulsion systems is envisioned.

\section{REFERENCES}

1. Hunter, Gary W.; "A Survey and Analysis of Commercially Available Hydrogen Sensors", NASA Technical Memorandum 105878, November 1992.

2. Hunter, Gary W.; "A Survey and Analysis of Experimental Hydrogen Sensors", NASA Technical Memorandum 106300, October 1992.

3. Lundstrom, I.; Armgarth, M.; and Petersson, L.; "Physics with Catalytic Metal Gate Chemical Sensors, CRC Critical Reviews in Solid State and Materials Sciences", vol. 15, pp. 201-278, 1989.

4. Hughes, R.C.; Schubert. W.K.; Zipperian, T.E.; Rodriguez, J.L.; and Plut, T.A.;"Thin Film Palladium and Silver Alloys and Layers for Metal-InsulatorSemiconductor Sensors", J. Appl. Phys., Vol. 2, pp. 1074-1038, 1987.

5. Hunter, G.W.; Liu, C.C.; Wu, Q.H.; and Neudeck P.G.; "Advances in Hydrogen Sensor Technology for Aerospace Applications," Advanced Earthto-Orbit Propulsion Technology 1994. Huntsville, AL, May 17-19, 1994. NASA Conference Publication 3282, Vol. I, pp. 224-233. 1994.

6. Hunter, G.W.; Neudeck, P.G.; Chen, L.-Y.; Liu. C.C.; and Wu, Q.H..; Makel, D.B.; and Jansa, E.; "A Hydrogen Leak Detection System for Aerospace and Commercial Applications," presented at $31^{\text {st }}$ IAA/ASME/SAE/ASEE Joint Propulsion Conference and Exhibit, San Diego, CA. July 10-12.1995 (American Institute of Aeronautics and Astronautics, Washington. DC) Tech. Rep AIAA-95-2645, 1995.
7. Barnes H.L.; and Makel, D.B.; "Quantitative Leak Detection Using Microelectronic Hydrogen Sensors" presented at the $31^{\text {st }}$ AIAA Joint Propulsion Conference, San Diego CA, AIAA Paper 95-2648, 1995.

8. Logothetis, E.M.; "Automotive Oxygen Sensors," Chemical Sensor Technology, Vol. 3, N. Yamazoe, ed., Kodansha Lid., pp. 89-104, 1991.

9. Neudesk, P.G.; "Progress in Silicon Carbide Semicondictor Electronics Technology", Journal of Electronic Materials, vol. 24, pp. 283-288, 1995.

10. Baranzahi, A.; Spetz, A.L.; Glavmo, M.; Nytomt, J.; and Lundstrom I.; "Fast Responding High Temperature Sensors For Combustion Control", Proceedings, $8^{\text {th }}$ International Conference on Solid-state Sensors and Actuators, and Eurosensors IX, Stockholm. Sweden, pp. 741-744, 1995.

11. Chen, L.-Y.; Hunter, G.W.; Neudeck, P.G.; Knight, D.; Liu, C.C.; and Wu, Q.H.; "SiC-Based Gas Sensors", in Proceeding of the Third International Symposium on Ceramic Sensors, Anderson, H.U.; Liu, M.; and Yamazoe, N., ed., Electrochemical Society Inc., pp. 92-105, 1996.

12. Hunter, G.W.; Neudeck, P.G.; Chen, L.-Y.; Knight, I); Liu, C.C.; and Wu, Q.H.; "Silicon Carbide-Based Hydrogen and Hydrocarbon Gas Detection" presented at the $31^{\text {st }}$ AIAA Joint Propulsion Conference, San Diego, CA, AIAA Paper 95-2647, 1995.

13. Hur ter, G.W.; Neudeck, P.G.; Chen, L.-Y.; Knight, C.; Liu, C.C.; and Wu, Q.H.; "SiC-Based Schottky I liode Gas Sensors", Proceedings of International Conerence on $\mathrm{SiC}$ and Related Materials, Stockholm, Swe ten, Sep. 1-7, 1997.

14. Lei, J.F.; Plat. Met. Rev., 35, p. 65-72, 1991. 

\begin{tabular}{l|l|l} 
1. AGENCY USE ONLY (Leave blank) & 2. REPORT DATE & 3. REPC RT TYPE AND DATES COVERED
\end{tabular}

\section{TITLE AND SUBTITLE}

November 1998

Technical Memorandum

5. FUNDING NUMBERS

A Hazardous Gas Detection System for Aerospace and Commercial Ap slications

6. AUTHOR(S)

WU $-254-02-0 \mathrm{~A}-00$

G.W. Hunter, P.G. Neudeck. L.-Y. Chen. D.B. Makel, C.C. Liu,

Q.H. Wu. and D. Knight

7. PERFORMING ORGANIZATION NAME(S) AND ADDRESS(ES)

National Aeronautics and Space Administration

Lewis Research Center

Cleveland, Ohio $44135-3191$

8. PERFotMing ORganization REPORT NUMBER

E-11419

9. SPONSORING/MONITORING AGENCY NAME(S) AND ADDRESS(ES)

National Aeronautics and Space Administration

Washington. DC 20546-()(0)1

10. SPONSORING/MONITORING AGENCY REPORT NUMBER

NASA TM-1998-208817

AIAA-98-3614

\section{SUPPLEMENTARY NOTES}

Prepared for the 34th Joint Propulsion Conference and Exhibit cosponsored by AIAA, ASME, SAE, and ASEE, Cleveland, Ohio, July 12-15, 1998. G.W. Hunter, P.G. Neudeck, and L.-Y. Chen, NASA Lewis Research Center; D.B. Makel, Makel Engineering. Chico. California 9597.3; C.C. Liu and Q.H. Wu. Case Western Reserve University, Electronics Design Center. Cleveland, Ohio 44106: D. Knight, Cortez III Service Corporation, Cleveland, Ohio 44135. Responsible person, G.W. Hunter, organization code 5510. (2I6) 433-6459.

\begin{tabular}{l|l} 
12a. DISTRIBUTION/AVAILABILITY STATEMENT & 12b. DISTRIBUTION CODE
\end{tabular}

Unclassificd - Unlimited

Subject Category: 35

Distribution: Non tandard

This publication is available from the NASA Center for AeroSpace Information. (30) $621-0390$.

\section{ABSTRACT (Maximum 200 words)}

The detection of explosive conditions in aerospace propulsion applicat ons is important for safety and economic reasons. Microfabricated hydrogen, oxygen, and hydrocarbon sensors as well as the accompanying hardware and software are being developed for a range of aerospace safety applications. The development of these sensors is being done using MEMS (Micro ElectroMechanical Systems) based technology and SiC-based semicondu ztor technology. The hardware and software allows control and interrogation of each sensor head and reduces accompanyin s cabling through multiplexing. These systems are being applied on the X-33 and on an upcoming STS-95 Shuttle mission. I number of commercial applications are also being pursued. It is concluded that this MEMS-based technology has significa it potential to reduce costs and increase safety in a varicty of aerospace applications.

\section{SUBJECT TERMS}

\begin{tabular}{l|l}
\hline 15. NUMBER OF PAGES \\
\hline
\end{tabular}

Gas; Leak: Hydrogen; Detection

17. SECURITY CLASSIFICATION OF REPORT

Unclassified

18. SECURITY CLASSIFICATION
OF THIS PAGE
Unclassified

19. SECURIT CLASSIFICATION OF ABST ZACT

Ur classified 